\title{
SEM MEDO DO FUTURO: ÉTICA DO JORNALISMO, INOVAÇÃO E UM APELO À FLEXIBILIDADE ${ }^{1}$
}

\author{
Jane B. Singer \\ Jane.Singer.1@city.ac.uk \\ Professor of Entrepreneurial Journalism, City University London \\ Northampton Square, EC1V oHB, London (UK)
}

\begin{abstract}
RESUMO
Os jornalistas desde sempre usaram os princípios éticos tanto para definir o que são como para indicar como devem actuar. A ética tornou-se um marco fronteiriço para distinguir jornalistas de não-jornalistas, e práticas familiares de práticas desconhecidas. Em resultado disso, os jornalistas tendem, num primeiro momento, a encarar qualquer nova abordagem ao campo da informação como uma ameaça aos princípios normativos por que se regem - ou seja, algo a que se deve resistir com base em razões morais. Tal resistência transforma-se facilmente num impedimento para pensar de modo produtivo sobre os modos como se pode responder positivamente à inovação. Este ensaio propõe que os jornalistas encarem a mudança perguntando como podem adaptar-se às novas realidades, ao mesmo tempo que preservam os seus valores essenciais.
\end{abstract}

\section{Palavras-Chave}

Ética do jornalismo; redes sociais; mudança; inovação; flexibilidade

Desde há muito tempo - desde há mais de um século, desde que os jornalistas começaram a considerar-se membros de uma profissão e não de uma simples ocupação - que os princípios éticos são usados não só para sugerir como é que os jornalistas devem comportar-se, mas também para definir o que é que eles são.

A ética é usada como uma espécie de marco fronteiriço para distinguir o familiar do desconhecido, assim como para desenhar um círculo figurativo que nos envolve e protege a "nós" ao mesmo tempo que os exclui a "eles", a todas aquelas pessoas que são Não-Jornalistas (Schudson \& Anderson, 2009). Os princípios normativos fundamentais são invocados para distinguir um confortável conjunto de práticas que conhecemos (e um conjunto de colegas praticantes com quem nos identificamos) daquelas que desconhecemos - e que, como seres humanos que somos, tendemos a recear. Esses mesmos princípios também dão aos jornalistas os argumentos para justificar esse receio.

Mas há aqui um problema. É muito fácil transpor a linha que separa o uso da ética como uma causa legítima do uso da ética como uma muleta. Quando a reacção a qualquer coisa que não nos é familiar nos leva a encará-la como um desafio terrível aos nossos princípios normativos - ou seja, como qualquer coisa a que devemos resistir por razões de ordem moral - a nossa resistência altera-se facilmente de uma auto-afirmação profissional para uma auto-destruição.

' Este artigo teve origem numa apresentação feita pela autora no Simpósio Internacional de Jornalismo Online, realizado em Austin, Texas, EUA, em Abril de 2014. 
A resistência traduz-se habitualmente em duas formas, por vezes sobrepostas. Uma é afirmar que as pessoas que fazem essas novas coisas não são jornalistas e não precisam de assegurar (e, em consequência, não asseguram mesmo) o respeito pelos padrões por que se regem os "verdadeiros" jornalistas. Outra é defender que devemos ser nós, os verdadeiros jornalistas, a fazer essas novas coisas - e de facto já nos estão a pedir, ou até a exigir, que as façamos - e a aplicar a esses processos os nossos padrões éticos.

Sempre acreditei firmemente na centralidade dos princípios éticos, numa altura em que os jornalistas transitam para o contexto digital. A adesão a normas que reforçam o nosso compromisso com a difusão de informação verdadeira e fiável é, em princípio, mais importante do que nunca num tempo em que estamos rodeados de informação de proveniência duvidosa e de qualidade discutível. Os jornalistas já há muito perderam o seu monopólio como fornecedores de informação à sociedade, pelo que é essencial que eles nunca percam a capacidade de garantir que o seu contributo é credível e que as suas acções estão ao serviço do bem público.

Porém, a reacção à novidade como se de uma ameaça moral se tratasse é irritante e frustrante, porque impede que se pense de modo mais produtivo, desde a base, sobre como responder à inovação do modo mais adequado. Os jornalistas já desperdiçaram muitas vezes um tempo valioso a sofrer com as mudanças, para depois desatarem a correr na tentativa de reconquistar o terreno que inevitavelmente foram perdendo para os inovadores que iam surgindo.

Uma alternativa mais interessante é a que proponho: começar na ofensiva e não na defensiva. Como podemos nós, enquanto jornalistas, adaptar-nos a esta nova coisa, ao mesmo tempo que preservamos os nossos valores essenciais? Em vez de perdermos tempo e energias mentais a explicar porque é que esses valores sucumbem perante as mudanças, vamos começar a pensar criativamente sobre os modos como podemos fazer com que eles se adaptem aos novos contextos.

Este ensaio apresenta uma série de exemplos, a maior parte (embora não todos) retirados de estudos académicos, sobre os modos como os jornalistas foram respondendo à inovação nas últimas duas décadas, desde que a Internet surgiu como um meio de utilização pública generalizada. Naturalmente, as citações que se seguem não representam a reacção de todos. Há muitos jornalistas com pontos de vista bastante diferentes, e alguns aderiram às mudanças logo que elas aconteceram, vendo neste meio emergente um lugar de incríveis oportunidades para melhorarem o seu trabalho e o respectivo impacto. Por outro lado, estas citações também não são exemplos fortuitos. Falando com jornalistas ao longo dos últimos 20 anos, ouvi repetidamente estes mesmos sentimentos, e outros investigadores ouviram-nos também. Muitos profissionais reagiram negativamente a cada uma das vagas de mudança - e, ao fazê-lo, tenderam a invocar preocupações éticas como justificação para o seu desejo de ficarem o mais longe possível destas inovações. 


\title{
A INTERNET: DE MEADOS A FINAIS DOS ANOS 1990
}

\begin{abstract}
"Na imprensa, sempre pudemos dar-nos ao luxo de... bem... vamos ver se aquilo que temos para publicar é verdadeiro e completo, e se pode ser verificado. O velho ditado era 'Agarra isso primeiro, mas, primeiro, agarra isso de modo correcto ['Get it first, but first, get it right']'. Pois bem, agora é só 'agarra isso primeiro'..." (jornalista de jornal dos EUA, Singer, 1997a: 82).
\end{abstract}

\begin{abstract}
"A Internet trabalha com alguma informação falsa que é apresentada como sendo real. Julgo que a questão maior que isso levanta é: quem é que pode/ deve ser responsabilizado?" (jornalista de jornal dos EUA, Singer, 1997b: 8o-81).
\end{abstract}

"Em vez de gatekeepers, vamos tornar-nos porteiros e porteiras, submetendo-nos a todo e qualquer capricho dos leitores e preocupando-nos em não os ofender com notícias negativas e muito realistas" (jornalista de jornal dos EUA, Singer, 1997b: 10).

No ambiente online, podemos escolher aquilo que queremos ler, e se a única coisa sobre que nos interessa ler é armas e munições, podemos fazer isso até ao fim da vida, nunca olhando para algo de diferente" (jornalista de jornal dos EUA, Singer, 1997a: 82).

Embora cientistas e investigadores já usem a Internet há muitos anos, ela só se tornou um meio para as pessoas comuns - e, entre elas, os jornalistas - com a invenção de um interface gráfico fácil-de-usar em meados dos anos 1990. Os primeiros sistemas de navegação [browsers] da Web foram disponibilizados em 1994 e 1995; nos anos imediatos, milhares de organizações em todo o mundo criaram websites e começaram a produzir conteúdos para lá colocar. As reacções iniciais dos jornalistas mostraram preocupação com questões de privacidade, de rigor e de autonomia (Deuze \&Yeshua, 2001), bem como com os potenciais prejuízos para uma sociedade bem informada (pelos jornalistas, claro).

Contar a verdade sempre foi encarado como uma virtude primeira e um mandato central dos jornalistas (Christians \& Cooper, 2009; Laitila, 1995). Ora o novo meio rapidamente foi rotulado como tendo, pelo menos, o potencial para a disseminação tanto deliberada como descuidada de não-verdades. Alguns jornalistas, mesmo antes de terem começado a usar a Internet, já manifestavam o receio de que a sua ênfase na rápida divulgação da informação subvertesse os procedimentos de verificação que funcionam como salvaguardas face a eventuais erros. Uma outra preocupação era a dificuldade de distinguir entre facto e ficção num meio em que os indicadores de credibilidade podiam ser facilmente imitados por qualquer um, sem que alguém assumisse claramente a responsabilidade pelas matérias difundidas, a exemplo do que acontece com a responsabilidade de um jornal por aquilo que publica ou de uma televisão por aquilo que emite. 
A autonomia é outra das normas essenciais do jornalismo, tal como de todas as ocupações cujos praticantes se consideram a si próprios como profissionais (Larson, 1977). Os jornalistas sempre defenderam acerrimamente o seu papel como gatekeepers independentes - um papel que se baseia na sua capacidade para julgarem por si próprios o que é e não é notícia e, assim, servirem um vagamente definido interesse público. Embora sempre tenham dado grande atenção à necessidade de se manterem independentes do governo e de interesses comerciais, os jornalistas também foram resistindo continuadamente aos apelos para interagirem mais com as suas audiências e para lhes prestarem contas; de acordo com alguns críticos (McDevitt et al., 2002), eles habituaram-se a invocar a autonomia como um modo de resistir aos apelos para um mais consequente envolvimento cívico. A natureza da Internet, que permite comunicação nos dois sentidos, suscitou-lhes, desde o início, receios

Mais genericamente, os jornalistas alimentam uma forte crença na sua relevante função ética enquanto fornecedores de um efectivo serviço público, e a concepção de si próprios como vigilantes [watchdogs] dos poderosos é uma componente central da ideologia jornalística (Deuze 2005). A ideia subjacente é, naturalmente, que a exposição a uma cobertura noticiosa cuidadosamente preparada por gatekeepers profissionais terá como consequência uma população bem informada sobre uma série de assuntos que importam: política, temas nacionais e internacionais, economia, actividade das instituições sociais, e mesmo algumas diversões criteriosamente escolhidas - a história de interesse humano, a crítica de um filme, a actualidade desportiva - misturadas no conjunto para aliviarem um pouco a carga pesada de uma cidadania responsável. Mas, mais uma vez, desde o princípio da Internet se tornou evidente a capacidade dos utilizadores online para deixarem de lado as notícias consideradas pelos jornalistas como as mais importantes e irem eles próprios directamente às que lhes interessam. E se tudo o que lhes interessa é apenas "armas e munições", bem, então o mundo tornar-se-á rapidamente um lugar muito pobre em termos informativos.

\section{ConvergênCia E Multimédia: o FinAl dos ANos 1990 E o inÍCIO dos ANOS 2000}

"Fui para uma escola de Jornalismo para ser jornalista, não para ser um trabalhador multimédia, não para ser uma pessoa da TV, não para as tarefas múltiplas [multitask]... Nunca gostei do jornalismo de televisão. Sempre o considerei uma sub-espécie, algo de repugnante" (jornalista de um jornal dos EUA; Singer, 2004: 14).

"Se eu tenho de correr para a redacção para pôr a história pronta numa hora, não posso ficar nos sítios a tentar obter mais uma entrevista ou a investigar mais profundamente. Mas era o que faria se estivesse a trabalhar apenas para o jornal Uornalista de um jornal espanhol; Avilés \& Carvajal, 2008: 231). 
"Se nos tornamos escravos de meios de entretenimento apenas, talvez tenhamos perdido alguma coisa. Ainda não aconteceu, mas é bem possível" (jornalista de um jornal dos EUA; Singer, 2006: 43).

Por volta do ano 2000, a "bolha digital" [dot com bubble] rebentou nos EUA, com repercussões globais. Após vários anos de crescimento meteórico de uma série de empresas do universo online - muitas delas assentes em financiamentos de curto prazo provindos de capitalistas especuladores e não em modelos de negócio sustentáveis - assistiu-se a uma súbita e dramática retracção. Embora as empresas de media que tinham lançado websites nos final dos anos 1990 estivessem por essa altura empenhadas em garantir uma presença online, ainda poucas tinham retirado lucros dessa presença. E tentaram encontrar maneiras de conseguir mais utilizadores para as suas páginas (o que, nas suas cabeças ainda habituadas a pensar nos modelos tradicionais de publicidade, significaria automaticamente mais receitas), sem gastar muito dinheiro nesses processos.

Duas estratégias comuns, e inter-relacionadas, foram adicionar "multimédia" conteúdos de áudio e vídeo, cuja criação e edição não requeriam grandes conhecimentos, dadas as novas tecnologias disponíveis, mesmo que ainda pouco sofisticadas - e fazer experiências de "convergência" nas redacções, combinando jornalistas, produtos, tecnologias, numa aproximação geográfica das anteriormente separadas províncias do impresso, da televisão e dos media online (Singer, 2004). Subitamente, os editores começaram a pedir aos repórteres que também captassem imagens de vídeo nos locais dos eventos ou que fizessem pequenos relatos noticiosos em frente a uma câmara; jornalistas da televisão eram solicitados a escrever colunas de opinião para o jornal do fim-de-semana ou a promover, nos seus noticiários, as histórias que sairiam no jornal do dia seguinte.

Como seria de esperar, muita gente nas redacções ficou chocada. Os jornalistas de imprensa, em particular, já tinham o hábito antigo de apoucar os seus colegas da televisão, encarando-os, nas palavras de um repórter de jornal, como "spray no cabelo, gravatas elegantes e cabeças ocas" (Singer, 2004: 10) - ou seja, como pessoas que não eram "verdadeiros" jornalistas, mas uma "sub-espécie repugnante" (ibid.: 14). Outros davam uma justificação mais explicitamente normativa para as suas preocupações. Por exemplo, alguns jornalistas de imprensa consideravam que os seus colegas da televisão eram menos "meticulosos" a verificar a informação ou a corrigir os erros, enquanto outros receavam que a convergência conduzisse à proliferação de "histórias espectaculares, orientadas para a TV" [TV-oriented], em prejuízo de peças noticiosas mais orientadas para a compreensão das questões [issue-oriented], como é mais próprio da imprensa (Singer: 41-42).

Estas preocupações e muitas outras, como os próprios jornalistas reconheceram, tinham mais a ver com algo que poderia vir a acontecer do que com algo que já acontecera de facto. Por exemplo, um repórter de imprensa confessou que sentia sempre um certo desconforto quando pensava nos modos como a empresa que patrocinava o seu programa semanal na televisão poderia pôr em perigo a sua independência - mesmo sabendo, conforme admitiu, que a empresa patrocinadora nunca tentara influenciar 
qualquer das peças jornalísticas do programa (Singer, 2006: 45). Igualmente preocupante, neste mesmo estilo de "e se...?", era uma potencial mudança de enfoque noticioso, menos voltado para os assuntos da comunidade e mais interessado em gerar tráfego para o website e audiências, particularmente tendo em conta a colaboração crescente com colegas que "vivem e morrem" por "taxas de audiência medidas a todo o momento". A ameaça aos princípios de serviço público e o risco de se tornarem "escravos de media de entretenimento", eram hipotéticos, mas o facto é que os jornalistas encaravam tais perigos de modo muito vivo (ibid.: 43).

Quanto à criação de conteúdos multimédia - algo que, de acordo com inquéritos internacionais, os jornalistas consideram cada vez mais uma competência vital (Willnat et al., 2013) - alguns admitem que estavam, muito simplesmente, com medo face ao desconhecido. Mas outros, como seria de imaginar, associam esse medo a preocupações éticas, enfatizando os efeitos negativos na qualidade das notícias e a escassez de tempo para um trabalho noticioso sério, ou ambos. Ter de correr para a redacção para criar e editar uma peça multimédia consome o tempo disponível "para obter mais uma entrevista ou investigar mais profundamente" (Avilés \& Carvajal, 2008: 231). "Eu sou como um pato", comentou um repórter de um jornal americano. "Já tenho que dar às pernas o mais depressa que consigo" (Singer, 2004: 12)

\section{BLOGGERS: InÍCIO DOS ANOS 2000}

“É jornalismo de vaidade. 'Olha para mim, eu expresso a minha opinião sobre qualquer assunto'. E eu sou muito jornalista à moda antiga, sabe, ainda dou o maior valor à correcção de processos, ao equilíbrio e a essas coisas todas. E em termos gerais não estou muito preocupado com o que possam pensar certas pessoas mal informadas mas que se consideram grandes especialistas. Porque basicamente bebem a água do seu próprio banho" (Jornalista da televisão canadiana, Bivens, 2008: 119).

Os bloggers “publicam porque ouvem 'alguma coisa' de 'alguém' que é 'de confiança'. Desculpem, mas isso não chega" (Jornalista de jornal americano, Carlson, 2007: 274).

“Escrever em blogues não é jornalismo. Muitas vezes é o mais distante que se pode estar do jornalismo, com rumores sem qualquer fundamento, preconceitos e mexericos disfarçados de opinião bem informada" (Colunista e crítico de assuntos de tecnologia na Grã-Bretanha; Hermida, 2008: 275-276).

Escrever em blogues é "pouco mais do que propaganda, servida em boa medida por pessoas desqualificadas [unemployable] a pessoas inúteis [aimless]" (Jornalista de uma revista americana e consultor; Rothenburg, 2004). 
Se a convergência e o multimédia ameaçavam roubar o tempo que os jornalistas consideravam mais necessário para a produção de jornalismo "de qualidade", os bloggers ameaçavam roubar-lhes a própria identidade. À medida que as plataformas de auto-publicação fáceis de usar se tornaram largamente acessíveis, as implicações de um medium verdadeiramente aberto, interactivo e livre de quaisquer entraves, saltaram à vista. Uma grande e inevitável implicação foi o facto de os bloggers terem reivindicado entrar no território próprio dos jornalistas: selecionar eventos e temas para as audiências, comentar esses temas, inclusivamente pesquisar e tratar informação de primeira mão (embora, nestes casos, mais através de acções de compilação de notícias de outros meios do que de investigação pessoal) (Lowrey, 2006). Os jornalistas rapidamente se empenharam em traçar linhas de demarcação na ciber-areia: de um lado, os verdadeiros jornalistas, que valorizam " a correcção de processos, o equilíbrio e essas coisas todas" (Bivens, 2008: 119); do outro, os exibicionistas, com os seus blogues "mal informados" e opinativos, voltados para si próprios.

Uma das principais normas que os jornalistas invocaram para se diferenciarem dos bloggers foi uma certa forma de independência, definida de modos variados como neutralidade, imparcialidade ou objectividade - ou seja, um lugar-comum contestado, mas exemplar no quadro da reivindicação dos jornalistas ao profissionalismo e ao poder que lhe está associado (Schudson \& Anderson, 2009). Os bloggers depressa se afirmaram como pessoas que davam as suas opiniões pessoais sobre as notícias, e os jornalistas depressa contrapuseram que a mistura de opinião e informação era um problema ético. "Os bloggers não estão a pregar para o coro. Eles são o próprio coro", escreveu um colunista de jornal em 2004. "Isto não é jornalismo honesto, independente e objectivo. E nem tenta sê-lo sequer" (Carlson, 2007: 268). Um colunista de outro jornal concorda: "Actuando no meio online, livres das normas jornalísticas tradicionais, os bloggers não têm de ser objectivos ou politicamente correctos" (ibid.: 272). Num texto para a influente revista de negócios Adverting Age, um articulista considerou que ser blogger era "pouco mais do que propaganda, servida por pessoas desqualificadas [unemployable] a pessoas inúteis [aimless]" (Rothenberg, 2004), e o certo é que os jornalistas e os seus patrões, pelo menos de vez em quando, levaram estas considerações à letra.

Naturalmente, à medida que se tornou normal os jornalistas produzirem conteúdos (incluindo multimédia) para meios online, também se vulgarizou a criação, pelos próprios jornalistas, de blogues no seio das suas empresas informativas. Mas mantiveram-se as preocupações sobre se, e como, deveriam manter uma postura de neutralidade. Uma série de afirmações de jornalistas da BBC, que criaram o seu primeiro blogue (integrado na redacção) em Dezembro de 2005 mas que, passados três anos, já tinham mais de 80 a funcionar, ilustram bem esta tensão. A citação apresentada atrás, sugerindo que os blogues "estão tão distantes do jornalismo como é possível estar" (Thompson, 2003), foi retirada de um texto escrito para o website da BBC, e os próprios jornalistas da BBC foram ainda mais explícitos. Os blogues "podem, embora isso pareça estranho, estar em sintonia com alguns dos princípios editoriais da BBC: verdade e rigor, imparcialidade e diversidade de opiniões, integridade editorial e independência, 
serviço do interesse público, correcção e respeito pela privacidade" (Hermida, 2008: 276) - isto escrito pelo homem que na altura era o editor da BBC responsável pelos blogues internos. E o editor da BBC responsável pelo online punha as coisas deste modo: "O que nós explicamos a todos os nossos bloggers, e felizmente todos eles percebem, é que eles não podem interpretar o ambiente aparentemente informal de um blogue como uma permissão para deixarem cair a exigência de imparcialidade" (ibid.: 277). "As regras aplicam-se tanto ali como nos canais tradicionais - imparcialidade é a palavra de ordem. O que significa que os bloggers têm de seguir um caminho cuidadoso: podem comprometer-se e fazer juízos de valor, mas não podem tomar partido", dizia um dos jornalistas da BBC que se tornou também blogger. "Não podemos, e não queremos, escrever textos de alguma forma parciais [partisan]"(ibid.: 276-277). Mesmo quando os jornalistas foram ganhando sucesso como bloggers, a norma tradicional da imparcialidade - uma norma inscrita na Carta da BBC - continuou a significar, pelo menos na sua perspectiva, uma linha de clara demarcação entre eles próprios e os bloggers não ligados a empresas informativas.

Uma outra preocupação ética que os jornalistas desde cedo expressaram tinha a ver com o facto de os materiais publicados nos blogues não serem verificados - e, portanto, não merecerem confiança. Aliás, os jornalistas caracterizavam os métodos de verificação dos bloggers como preguiçosos e descuidados - ou seja, práticas "não suficientemente boas" (Carlson, 2007: 274). Um académico sintetizou assim esta preocupação em 2004, numa coluna de jornal: "Não há qualquer teste de credibilidade" para as fontes de um blogger. "Se um artigo aparece no Washington Post, no The New York Times ou no Omaha World-Herald, eu sei que ele foi revisto por alguém cuja profissão exige que se confirme a credibilidade das fontes. Com um blogue, não fazemos a mínima ideia" (Carlson, 2007: 274). Um inquérito feito em meados dos anos 2000 constatou que um grande número de jornalistas considerava os blogues pouco fiáveis, achando-os nem credíveis nem factuais (Chung et al., 2007). Com efeito, a disciplina da verificação era a prática diferenciadora, bem ilustrativa daquilo a que um colunista de várias publicações impressas identificou como a "desconexão" [disconnect] entre bloggers e jornalistas. "Os bloggers, em geral, sabem pouco sobre verificação independente de dados e de informação. Faltam-lhes os instrumentos e a experiência para investigação aprofundada. Não sabem como confirmar os factos [fact-check]", escreveu ele (Andrews, 2003). "Chamar jornalista a um blogger é como chamar fotógrafo a alguém que tira casualmente umas fotografias".

Não por acaso, estas críticas ligadas com a imparcialidade e com a verificação chamaram a atenção para uma norma que, embora não sendo nova, se adequava particularmente bem ao espírito de um medium interactivo: a transparência. O conhecimento público do background dos bloggers, das suas motivações e de eventuais interesses financeiros, foi considerado de enorme importância, tendo surgido exemplos de bloggers muito conhecidos que apostaram em disponibilizar informação detalhada sobre si próprios (Trammell \& Keshelashvili, 2005). 
Rapidamente muitos jornalistas se tornaram também "j-bloggers" - não obstante os consideráveis receios dos seus patrões de que eles pudessem dizer coisas embaraçosas em público (Outing, 2004). Embora as normas jornalísticas tradicionais da objectividade e do distanciamento tornassem difícil a muitos jornalistas uma total 'declaração de interesses' (Hayes et al., 2006), muitos acabaram por se sentir mais confortáveis ao admitirem que, afinal, também são seres humanos. Claro que rapidamente passaram a considerar esta nova exigência perfeitamente justificada, e até requerida pela - que mais havia de ser? - ética profissional, em especial pelo dever de prestar contas ao público através de formas mais completas de contar a verdade. A "missão fundamental" de um blogue noticioso da CBS, por exemplo, era tornar mais transparentes os processos da estação, permitindo que ela fosse "mais aberta acerca do 'como' e do 'porquê' das suas decisões editoriais" (Meyer, 2005: 1, 4). "Temos de abraçar a transparência", dizia o anterior Provedor do Leitor do Washington Post. "Isso faz parte do processo que nos deve tornar mais responsabilizáveis [accountable] perante um público que há muito se interrogava sobre quem vigia os vigilantes" [who's watching the watchdogs]. Em resumo, os jornalistas deram a volta completa ao círculo: apropriaram-se de uma norma dos blogues para justificar por que razão o conteúdo jornalístico era, de facto, moralmente superior (Karlsson, 2011).

\section{CoNTEÚdos GERAdos PELO UTILIZADOR: DE MEAdos A FINAIS DOS ANOS 2000}

Quando estão envolvidas pessoas que não são jornalistas profissionais, vê-se que elas não fazem a mínima ideia das questões éticas... Arriscam-se a diluir as notícias em rumores e mexericos" (Jornalista de um jornal americano; Lewis et al., 2012: 170).

"Chegam a ser tratadas como factos coisas que nada nos permite garantir que são factos" (Jornalista de um jornal americano; ibid.).

O valor dos conteúdos gerados pelo utilizador é "desproporcionado face à quantidade de tempo que nos toma para tentarmos assegurar que são conteúdos rigorosos, equilibrados, honesto, correctos e - mais importante de tudo - legalmente seguros para publicação" (Jornalista de um jornal britânico; Singer, 2010: 134).

Passemos para a segunda metade da década de 2000, quando os jornalistas (incluindo os j-bloggers) se debatiam com os conteúdos gerados pelos utilizadores, muitos deles sob a forma de comentários ligados aos seus artigos. Se os bloggers desafiavam a reivindicação ocupacional dos jornalistas de que eram os únicos criadores de conteúdos com valor informativo sobre a actualidade, o facto é que os conteúdos gerados pelos utilizadores significavam que eles (jornalistas) estavam a perder o controlo sobre o que era publicado online, mesmo quando isso sucedia junto às suas próprias assinaturas e à 
sombra do título para que trabalhavam. Eles perdiam pouco tempo a tentar explicar por que motivo esses conteúdos não eram, nem poderiam ser nunca, jornalísticos - ou seja, por que motivo eles significavam uma ameaça real aos valores editoriais e aos padrões jornalísticos -e, como tinham feito desde sempre, continuavam a basear a sua definição de jornalismo em sólidos princípios éticos.

As preocupações éticas sobre os conteúdos gerados pelo utilizador, em especial os das caixas de comentários, eram muito variadas, mas as questões de rigor, de credibilidade e de civismo tendiam a ser as mais destacadas. A primeira (rigor) estava mais uma vez ligada directamente à dificuldade de verificar a informação - podia ser factual, mas podia ser também apenas "rumores e mexericos" (Lewis et al., 2010: 170) - fornecida por pessoas que um jornalista tem motivos para acreditar que são responsáveis, mesmo que não tenha qualquer controlo sobre elas. Os jornalistas sentiam que a sua credibilidade estava ameaçada. Quando os jornalistas escrevem uma peça, "falamos pelo menos com três fontes. Quando publicamos alguma coisa, sabemos que é o mais próximo da verdade a que nos foi possível chegar", dizia um jornalista americano. "Quando nos aparece um cidadão a falar de uma queixa sobre a polícia, aquilo vai ser uma mistura de opinião e de factos. E isso afecta a credibilidade da nossa organização" (Lewis et al., 2010: 170). Uma editora de um medium britânico dizia que não tinha qualquer expectativa sobre a credibilidade dos utilizadores, baseando-se na falta de informação sobre "o que eles sabem, o que eles não sabem, que motivações têm e em que perspectivas se colocam" (Singer \& Ashman, 2009: 13). Outra era ainda mais dura: "As nossas plataformas emprestam credibilidade a pessoas cujos comentários são, por vezes, totalmente falhos de rigor, ofensivos e não fundamentados em factos. Isso arrisca-se a minar o trabalho dos jornalistas profissionais, pois coloca as palavras de pessoas que não têm qualquer formação específica ou responsabilidade profissional no mesmo plano das de pessoas que as têm" (ibid.: 12-13). Deus nos valha.

Para além disto, na opinião dos jornalistas, os utilizadores não se sentem necessariamente obrigados a prestar contas por aquilo que publicam - ao contrário dos jornalistas. O à-vontade com que os utilizadores - mais uma vez, ao contrário dos jornalistas - publicam as suas notícias e opiniões anonimamente tem sido referido como um indicativo desta falta de responsabilização e como um factor que contribui para comportamentos abusivos no universo online. O uso de pseudónimos tem servido para que se seja injurioso com total impunidade (Singer, 2010). Porque escrevem anonimamente, comenta um jornalista britânico, "as pessoas sentem-se livres para dizer coisas, na forma e no conteúdo, que nunca publicariam se assinassem com o seu próprio nome (Singer \& Ashman, 2009: 16). E os jornalistas foram vendo como a falta de civismo no universo online é agressiva. Um editor britânico, por exemplo, descreveu as trocas de comentários online como "uma série de comportamentos intolerantes... gente gritando de um lado da sala para o outro, e continuando a gritar, sem sequer se preocupar em ouvir o que a gente do outro lado está a dizer. E só por excepção alguém surge ali a apresentar um ponto de vista mais razoável e equilibrado" (Thurman, 2008: 144-145). Outro editor de um pequeno jornal descreveu "a maior parte" dos comentários online como 
"ordinários, ofensivos e geralmente sem qualquer interesse. Aquilo desvaloriza o nosso produto, e em alguns casos ofende as nossas fontes", que receiam tornar-se "presas atiradas aos cães" se por acaso o seu nome é citado num artigo (Singer, 2010: 134).

Os conteúdos gerados pelo utilizador trouxeram preocupações tanto legais como éticas. A necessidade de assegurar que materiais oriundos de fora da redacção eram "legalmente seguros para publicação" sempre tomou muito tempo e muitas energias aos jornalistas. Os comentários estão "sujeitos a processos judiciais por calúnia, a acusações de difamação, a regras de censura, à necessidade de omitir os nomes de vítimas de violação - ou seja, montes e montes de trabalho para ler todas estas coisas e para as aprovar", como explicava um editor israelita (Singer et al., 2010: 135). As questões de difamação sempre foram a maior preocupação legal: "O director de um jornal é responsável por tudo o que lá se publica, incluindo os posts oriundos das mais bizarras personagens da sociedade", dizia um editor canadiano (ibid., 2010: 131). Outras preocupações legais têm a ver com discursos racistas, particularmente em países como a Alemanha, que têm leis muito severas neste domínio, e com respeito pela propriedade intelectual, algo que, de acordo com os jornalistas, os "cidadãos normais" não percebem.

Há mais exemplos, claro, mas fica aqui a ideia geral. Convém salientar, entretanto, que estas críticas e preocupações não são universais: muitos jornalistas têm expressado o seu apoio a contribuições vindas dos utilizadores, embora não haja grandes certezas sobre a boa relação entre os custos reais e os benefícios efectivos destes processos. Ainda assim, muitos jornalistas, de diferentes media e diferentes países, acabaram por estabelecer um quadro de referência sobre as questões éticas suscitadas por estes novos contributos, assim como uma argumentação ética sobre o motivo por que isto não é jornalismo. Mais uma vez, traçaram uma linha divisória e colocaram-se imediatamente do lado dos anjos.

\section{MEDIA SOCIAIS: DO FINAL DOS ANOS 2000 AO INÍCIO DOS ANOS 2010}

"O Twitter inunda o mercado com os pensamentos privados de figuras públicas, muitos dos quais não têm interesse rigorosamente nenhum" (jornalista alternativo dos EUA; Arceneaux \& Weiss, 2010: 1271).

"Uma função dos media convencionais é difundir informação que consideramos digna de confiança... A confiança que nos merecem o Twitter e o Facebook está essencialmente em abrirmos as portas a tudo e a toda a gente" (jornalista de rádio dos EUA; Small, 2011: 873).

"Isto é como procurarmos aconselhamento médico na Internet, num mundo de charlatanices e curas milagrosas" (colunista americano; Hermida, 2010: 300). 
"Ficamos com a ideia de que há por aí muitíssima gente que funciona como sendo os nossos olhos e os nossos ouvidos. Podem ser realmente muito úteis... Mas a nossa grande vantagem é podermos ter um ecrã de computador num escritório em Londres, e enquanto jornalistas acabamos por descobrir muitas mais coisas nessa situação. Sempre (Jornalista de imprensa britânico; Thurman \& Walters, 2013: 93)

Desde os finais dos anos 2000, tempos de grande agitação económica e tecnológica, no domínio dos media mas não só, aos conteúdos gerados pelo utilizador vieram juntar-se os media socias. É a última das inovações da minha lista, mas, tal como com as outras, em termos gerais também suscitou o mesmo tipo de receios e desconfianças no plano ético. Facebook, Twitter, Tumblr, Instagram e mais uma série deles está, de facto, a abrir as portas "a tudo e a toda a gente". E como é que nós - assim como o público a quem servimos - conseguimos saber em quem ou em quê confiar?

Muitos dos formatos de media sociais, como o Twitter, são basicamente micro-blogues, e as preocupações que suscitam são muito semelhantes às suscitadas uns anos antes pelos blogues e, depois, pelos conteúdos gerados pelo utilizador. Mas, contrariamente aos comentários e a outros contributos para os websites noticiosos que são gerados depois de o jornalista ter publicado uma história, os media sociais são, potencialmente, fontes de informação. As questões sobre a sua fiabilidade, portanto, são uma preocupação mais directa. Será que aquela informação é suficientemente importante e credível a ponto de eu a incorporar numa história que tem o meu nome por baixo?

Muitos jornalistas começaram por duvidar. Um colunista veterano descreveu assim o Twitter em 2009: "Um brinquedo para celebridades entediadas e para meninas do liceu" (Hermida, 2000: 299) - por outras palavras, para pessoas cujas ideias não vale muito a pena conhecer, e muito menos partilhar. Outros jornalistas também ridicularizaram a trivialidade dos tweets, assim como a sua falta de seriedade e de interesse noticioso. "O que é que pode ser mais aborrecido e menos útil do que um site em que milhares de pessoas recebem a oferta de 140 caracteres para gritarem aos quatro ventos o que estão a fazer a cada instante do dia? E o que é espantoso é que imensa gente por aí pensa que este fluxo idiota de banalidades ('estou a comer uma tangerina', ' estou à espera do avião', 'quero um Big Mac') é suficientemente interessante para funcionar como uma plataforma viável de publicidade", escreveu um colunista em Advertising Age (Arceneaux \& Weiss, 2010: 1271), - a mesma publicação, se se lembram, que gozou com o potencial dos blogues uns anos antes.

Os perigos da informação instantânea, identificados pelos jornalistas logo que tomaram consciência de como funciona a Internet, tornam-se ainda maiores com o advento dos media socias, que combinam a acessibilidade a partir de qualquer lado com um processo de publicação incrivelmente fácil - e uma notável ausência de editores. "Esta foto, este vídeo, esta informação, são assim tão importantes ou urgentes que não possamos esperar um pouco e investigar melhor o assunto?", interrogava-se Craig Silverman, editor do blogue Regret the Error. "Não se pode começar a mandar coisas lá para fora e perguntar 'será que isto é verdade?' Não é assim que se age de modo responsável" 
(Bartlett, 2012). O risco potencial destes processos é tão grande que este ano o Centro Europeu de Jornalismo (European Journalism Centre - EJC) publicou um "Manual de Verificação" para ajudar jornalistas, bem como outros difusores de informação, a "recolher, triangular e verificar a informação frequentemente contraditória" que emerge dos media sociais, sobretudo quando ocorre um desastre (Silverman \& Tsubaki, 2014).

Os media sociais, tal como os blogues há uma década, também constituem um desafio para o tradicional estilo de escrita dos jornalistas, baseado na premissa de que o distanciamento é uma ajuda a, e um sinal de, uma imparcialidade normativamente desejável. Apesar de todos os desafios colocados pelo novo contexto digital dos media, a busca da objectividade continua a ser um elemento central das auto-percepções dos jornalistas enquanto profissionais com sentido ético (Schudson \& Anderson, 2009). No entanto, um estudo recente mostrou que uma grande percentagem de tweets dos próprios jornalistas continha pelo menos alguma expressão de opinião, constatando-se que eles usam este formato para partilhar informação sobre tudo, desde o seu trabalho às suas vidas pessoais (Lasorsa et al., 2012), e inclusive o humor, tornando assim o jornalista abertamente 'presente' nos seus escritos (Holton \& Lewis, 2011).

Mas isto não tem ocorrido sem problemas, como é fácil imaginar. As empresas de media têm-se debatido com dúvidas sobre que margem de liberdade devem dar aos seus jornalistas neste domínio, e algumas criaram regras internas semelhantes a esta (do jornal sul-africano Mail and Guardian): "A pedra angular da nossa autoridade enquanto publicação é a imparcialidade. Os vossos perfis pessoais, tweets e posts podem revelar as vossas simpatias políticas e ideológicas. Assegurem-se de que a vossa audiência compreende que vocês são suficientemente profissionais para deixar tais preferências de lado na altura do trabalho, ou então que essas simpatias não serão de molde a impedir que vocês façam jornalismo objectivo". E algumas empresas informativas até adoptaram medidas para refrear os jornalistas cuja actividade não respeite estas normas tradicionais nas redes sociais: o The New York Times, por exemplo, nomeou um editor para "acompanhar muito de perto" a presença nas redes sociais da responsável pela sua delegação em Jerusalém, depois de ela ter colocado no Facebook alguns comentários pouco cuidadosos sobre os palestinianos (Sullivan, 2012).

Dito isto, e apesar das naturais objecções, os media sociais foram adoptados pelos jornalistas mais depressa e com menos protestos do foro ético do que as anteriores inovações descritas atrás. E há indicações de que até as formas mais recentes do jornalismo empreendedor [entrepreneurial journalism] também não suscitam mais do que receios esparsos. (Vos \& Singer, 2014).

Este artigo termina com um olhar para o passado, para o presente e talvez para o futuro.

\section{FlexibiliddAe EM PRIMEIRO LUgAR}

Acredito firmemente que os jornalistas, e o público que eles servem, só têm vantagem em revisitar periodicamente as normas fundadoras da sua ocupação. Quando pensamos aprofundadamente, e com sentido crítico, nesses valores e nas razões para 
os preservarmos, fazemos uma pausa no ritmo frenético das nossas rotinas diárias e reavaliamos o papel que desempenhamos na sociedade, bem como a relevância desse papel. Períodos de transicção em geral, e as actuais transformações do digital em particular, não tornam a ética menos importante para os jornalistas. Pelo contrário, como eu disse no começo, um compromisso com uma prática eticamente exigente é mais importante do que nunca num tempo em que estamos imersos em informação de todos os tipos e de todos os níveis de qualidade. O facto de os jornalistas terem perdido o seu quase-monopólio enquanto fornecedores de informação à sociedade torna mais vital do que nunca que eles não desistam da sua legítima reivindicação ao estatuto de produtores de uma informação credível e fiável, que coloque o interesse público acima de tudo.

E, no entanto...

$E$, no entanto, as inovações sumariamente descritas atrás não significam o fim do bom jornalismo. Bem pelo contrário. Cada uma dessas inovações acaba, em última instância, por permitir, e até por facilitar, a produção de um jornalismo mais forte em diversos planos. A Internet, a possibilidade de incorporar som e imagem nas histórias, os novos formatos como os blogues, os conteúdos gerados pelo utilizador ou os media sociais - tudo isto contribui para um jornalismo que é mais atraente, mais multifacetado e mais acessível a mais pessoas, em mais lugares e de mais formas.

Os problemas dos media contemporâneos estão muito ligados à crise financeira, provocada pela falência (essa, sim, causada em larga medida pelas tecnologias digitais) de modelos económicos surgidos num contexto de escassez de informação que já não existe (Ryfe, 2012). Por outras palavras: a crise é uma crise económica, não uma crise do jornalismo. As ameaças éticas que os jornalistas receiam - e nem sempre sem razão - decorrem primariamente das pressões que advêm da falta de dinheiro, não do excesso de inovação. As organizações que ainda dão emprego à maioria dos jornalistas reduziram efectivos, cortaram nas despesas, pediram a cada vez menos pessoas que produzam mais com menos recursos. Não surpreende que esta seja uma receita propícia ao surgimento de erros, ao aligeiramento das práticas de verificação e à transferência, para os utilizadores, da produção de notícias que os jornalistas já não têm tempo ou meios para garantir.

Mas talvez estejamos, aqui, a confundir os efeitos com as causas. A causa das derrapagens éticas que os jornalistas tão facilmente conseguem apontar, em defesa das suas teses, não é a tecnologia per se - não é a Internet, não é o multimédia, não são os blogues ou os media sociais. Uma causa é a falta de recursos que permitam aos jornalistas lidar com essas coisas todas e com os desafios que elas colocam do modo completo - e ético - que eles desejariam. E outra causa é a falta de mentalidades abertas e inovadoras, de que as redacções também precisam.

Ainda estamos fixados no "primeiro, o digital" (ou talvez "primeiro, o móvel"), quando a nossa necessidade mais crucial é "primeiro, ser flexível". A vontade de nos adaptarmos permite-nos enfrentar a questão de saber como é que as nossas normas podem guiar a nossa adaptação desde o princípio. Por outras palavras, o objectivo deve ser construir padrões normativos que se ajustem à inovação jornalística, optando por 
uma resposta proactiva às inevitáveis mudanças em curso, ao contrário de uma resposta reactiva que deixa os jornalistas perpetuamente a correr atrás dos acontecimentos. Sem a flexibilidade necessária numa paisagem mediática em constante mudança, os jornalistas e as empresas de media continuarão a perder imenso tempo com angústias existenciais fúteis, quando esse tempo poderia ser aproveitado, de modo muito mais produtivo, a trabalhar para que as mudanças

Termino com um exemplo de como a inovação tecnológica não só pode conduzir, como de facto conduz, a um melhor jornalismo, quando os seus praticantes se deixam de angústias e metem mãos à obra, usando a sua sensibilidade ética específica para orientar as inovações num sentido de que possam orgulhar-se. O meu exemplo vem dos media sociais, particularmente do micro-blogue Twitter, que se tem tornado num meio que permite aos jornalistas não só aplicar, mas até expandir, importantes práticas normativas. Vejamos:

* Porque pode ser muito difícil distinguir tweets credíveis, enviados a partir de um evento noticioso, de outros que não são fiáveis, as organizações de media passaram a estar mais atentas e reforçaram os seus procedimentos de verificação. O serviço de notícias da agência Associated Press (AP), por exemplo, tem prevista uma série de passos a seguir para verificar a credibilidade de informação que lhe chega via Twitter, e esses passos vêm à frente do processo normal de verificação - não em vez dele. Incluem, entre outros, verificar a fonte da história nos media sociais, comparar a informação chegada via Twitter com outros materiais da AP e passar os materiais pelas mãos de peritos locais (Silverman, 2012).

* É uma questão de bom senso, há muito aceite no jornalismo, que quanto mais perspectivas recolhemos - e os hashtags do Twitter são, presentemente, imbatíveis quando queremos encontrar uma série de perspectivas - mais multifacetada é a verdade que se coloca à disposição dos cidadãos do mundo. Já não precisamos de depender apenas das fontes oficiais para sabermos o que está a acontecer em Pequim ou Washington ou Londres ou Lisboa. Actualizações, comentários e análises estão à nossa disposição não só muito mais depressa do que antigamente, mas também com origem num muito mais variado leque de fontes.

* Talvez ainda mais relevante: o Twitter obrigou os jornalistas a interiorizarem (agindo em consonância) a convicção de que existe uma relação entre eles e as suas audiências. Eles não estão separados das pessoas reais, apenas expedindo informação para elas a partir de dentro da redacção. Eles são parte de um ecossistema mediático que inclui outros seres humanos reais, vivos, e o seu relacionamento com esses seres humanos tem de ser aberto e honesto para funcionar. Os jornalistas que no passado prestavam pouco mais do que uma atenção retórica à norma ética da prestação de contas descobriram agora que têm de o fazer por actos, não apenas por palavras. Têm de poder ser responsabilizáveis, directa e imediatamente, por aquilo que dizem, que escrevem, que disponibilizam online - ou que difundem pelo Twitter. Têm de corrigir o que está errado. Têm de dizer o que é que não sabem, assim como aquilo que sabem. Em síntese, têm de fazer um trabalho conjunto e colaborativo de procura e partilha da informação, e não apenas um serviço de entrega das notícias. 
Em resumo, as normas jornalísticas fundamentais estão actualmente a tornar-se mais efectivas através do uso que os jornalistas lhes dão, não no formato tradicional mas em formatos novos. Estas e outras preocupações éticas no uso do Twitter e dos demais media sociais mostram jornalistas flexíveis e inovadores que, partindo dos princípios e valores de sempre, tentam proactivamente encontrar a forma adequada para os formatos digitais, de modos que tragam benefício social. Estes jornalistas não abandonaram a sua ética ao adaptarem-se aos media sociais. Em vez disso, aplicaram a sua ética de maneiras que tornam mais credíveis não só as mensagens dos media sociais, mas os próprios jornalistas.

\section{[Tradução: Joaquim Fidalgo]}

\section{REFERÊNCIAS}

Andrews, P. (2003, Outono). “Is Blogging Journalism?” Nieman Reports. Disponível em: http://www.nieman. harvard.edu/reports/article/101027/Is-Blogging-Journalism.aspx [acedido a 12 Maio 2014].

Arceneaux, N., \& Weiss, A. S. (2010). Seems Stupid until You Try It: Press Coverage of Twitter, 2006-9. New Media and Society $12(8): 1262-1279$.

Avilés, J. A. G., \& Carvajal, M. (2008). Integrated and Cross-Media Newsroom Convergence: Two Models of Multimedia News Production - the Cases of Novotécnica and La Verdad Multimedia in Spain. Convergence 14 (2): 221-239.

Bartlett, R. (2012, 3 Abril). "How To: Verify Content from Social Media." journalsm.co.uk. Disponível em: http://www.journalism.co.uk/news-features/how-to-verify-content-from-social-media/s5/a548645/ [acedido 13 Maio 2014].

Bivens, R. K. (2008). The Internet, Mobile Phones and Blogging: How New Media Are Transforming Traditional Journalism. Journalism Practice 2 (1): 113-129.

Carlson, M. (2007). Blogs and Journalistic Authority: The Role of Blogs in US Election Day 2004 Coverage. Journalism Studies 8 (2): 264-279.

Christians, C. G., \& Cooper, T. W. (2009). "The Search for Universals." In L. Wilkins and C.G. Christians (eds.), The Handbook of Mass Media Ethics: pp. 55-68. New York: Routledge.

Chung, D. S., Kim, E., Trammell, K. D., \& Porter, L. V. (2007). Uses and Perceptions of Blogs: A Report on Professional Journalists and Journalism Educators. Journalism Q Mass Communication Educator 62 (3): 305-322.

Deuze, M. (2005). What Is Journalism? Professional Identity and Ideology of Journalists Reconsidered. Journalism 6 (4): 442-464.

Deuze, M. \& Yeshua, D. (2001). Online Journalists Face New Ethical Dilemmas: Lessons from The Netherlands. Journal of Mass Media Ethics 16 (4): 273-292.

Harrison, J. (2010). User-generated Content and Gatekeeping at the BBC Hub. Journalism Studies 11 (2): 243-256.

Hayes, A. S., Singer, J. B., \& Ceppos, J. (2007). Shifting Roles, Enduring Values: The Credible Journalist in a Digital Age. Journal of Mass Media Ethics 22 (4): 262-279, 
Hermida, A. (2008). The Blogging BBC: Journalism Blogs at "the World's Most Trusted News Organisation." Journalism Practice 3 (3): 268-284.

Hermida, A. (2010). Twittering the News: The Emergence of Ambient Journalism. Journalism Practice 4 (3): 297-308.

Holton, A. E., \& Lewis, S. C. (2011). Journalists, Social Media, and the Use of Humor on Twitter. The Electronic Journal of Communication / La Revue Electronic de Communication 21 ( 1 and 2), Disponível em: http:// www.cios.org/EJCPUBLIC/O21/1/O21121.html [acedido 13 Maio 2014].

Karlsson, M. (2011). The Immediacy of Online News, the Visibility of Journalistic Processes and a Restructuring of Journalistic Authority. Journalism 12 (3): 279-295.

Laitila, T. (1995). Journalistic Codes of Ethics in Europe. European Journal of Communication 10 (4): 527-544.

Larson, M.S. (1977). The Rise of Professionalism: A Sociological Analysis. Berkeley: University of California Press.

Lasorsa, D. L., Lewis, S. C., \& Holton, A. E. (2012). Normalizing Twitter: Journalism Practice in an Emerging Communication Space. Journalism Studies 13 (1): 19-36.

Lewis, S. C., Kaufhold, K., \& Lasorsa, D. L. (2010). Thinking about Citizen Journalism: The Philosophical and Practical Challenges of User-Generated Content for Community Newspapers. Journalism Practice 4 (2): 163-179.

Lowrey, W. (2006). Mapping the Journalism-Blogging Relationship. Journalism 7 (4): 477-500.

McDevitt, M., Gassaway, B. M., \& Perez, F. G. (2002). The Making and Unmaking of Civic Journalists: Influences of Professional Socialization. Journalism Q Mass Communication Quarterly 79 (1): 87-100.

Meyer, D. (2005, 30 Agosto). “About Public Eye." CBS News. Disponível em: http://www.cbsnews.com/ stories/2005/08/30/publiceye/main805566.shtml [acedido14 Maio 2014].

Outing. S. (2004, 18 Fevereiro). "When Journalists Blog, Editors Get Nervous." Editor \& Publisher. Disponível em: http://www.editorandpublisher.com/PrintArticle/When-Journalists-Blog-Editors-Get-Nervous [acedido 12 Maio 2014].

Rothenberg, R. (2004, 8 Novembro). "Reports on Power of Blogs Have Been Greatly Exaggerated." Advertising Age. Disponível em: http://adage.com/article/randall-rothenberg/reports-power-blogsgreatly-exaggerated/101117/ [acedido 7 Maio 2014].

Ryfe, D. M. (2012). Can Journalism Survive? An Inside Look at American Newsrooms. Cambridge: Polity Press.

Schudson, M., \& Anderson, C. (2009). "Objectivity, Professionalism and Truth Seeking in Journalism." In K. Wahl-Jorgenson \& T. Hanitzsch (eds.), The Handbook of Journalism Studies: pp. 88-101. New York: Routledge.

Silverman, C. (2012, 16 Novembro). "Editor Fergus Bell explains how AP verifies user-generated content from Sandy to Syria." PoynterOnline. Disponível em: http://www.poynter.org/latest-news/regret-theerror/192540/new-editor-fergus-bell-explains-how-ap-verifies-user-generated-content-from-sandy-tosyria/ [acedido 8 Maio 2014].

Silverman, C., \& Tsubaki, R. (2014, 29 Janeiro). "Verification Handbook: Necessary Tools for Breaking News." Journalism.co.uk. Available at: http://www.journalism.co.uk/news/verification-handbook-necessarytools-for-breaking-news/s2/a555728/ [accessed 13 May 2014].

Singer, J. B. (1997a). Still Guarding the Gate? The Newspaper Journalist's Role in an On-line World. Convergence 3 (1, spring 1997): 72-89. 
Singer, J. B. (1997b). Changes and Consistencies: Newspaper Journalists Contemplate Online Future. Newspaper Research Journal 18 (2): 2-18.

Singer, J. B. (2004). Strange Bedfellows? The Diffusion of Convergence in Four News Organizations. Journalism Studies 5 (1): 3-18.

Singer, J. B. (2006). Partnerships and Public Service: Normative Issues for Journalists in Converged Newsrooms. Journal of Mass Media Ethics 21 (1): 30-53.

Singer, J. B. (2010). Quality Control: Perceived Effects of User-Generated Content on Newsroom Norms, Values and Routines. Journalism Practice 4 (2): 127-142.

Singer, J. B., \& Ashman, I. (2009). "Comment Is Free, but Facts Are Sacred": User-generated Content and Ethical Constructs at the Guardian. Journal of Mass Media Ethics 24 (3): 3-21.

Singer, J. B., Hermida, A., Domingo, D., Heinonen, A., Paulussen, S., Quandt, T., Reich, Z., \& Vujnovic, M. (2010). Participatory Journalism: Guarding Open Gates at Online Newspapers. Malden, Massachusetts: Wiley-Blackwell.

Small, T. A. (2010). What the Hashtag? A Content Analysis of Canadian Politics on Twitter. Information, Communication and Society 14 (6): 872-895.

Smolkin, R. (2006, Abril/Maio). "Too Transparent?” American Journalism Review. Disponível em: http:// ajrarchive.org/article.asp?id=4073 [acedido12 Maio 2014].

Sullivan. M. (2012, 28 Novembro). "Problems with a Reporter's Facebook posts, and a Possible Solution." The New York Times. Disponível em: http://publiceditor.blogs.nytimes.com/2012/11/28/ problems-witha-reporters-facebook-posts-and-a-possible-solution/ [acedido 13 Maio 2014].

Thompson, B. (2003, 21 Fevereiro). "Is Google Too Powerful?” BBC News online. Disponível em : http:// news.bbc.co.uk/1/hi/technology/2786761.stm [acedido1o Maio 2014].

Thurman, N. (2008). Forums for Citizen Journalists? Adoption of User Generated Content Initiatives by Online News Media. New Media a Society 200810 (1): 139-157.

Thurman, N., \& Walters, A. (2013). Live Blogging - Digital Journalism's Pivotal Platform? A Case Study of the Production, Consumption, and Form of Live Blogs at Guardian.co.uk. Digital Journalism 1 (1): 82-101.

Trammell, K. D., \& Keshelashvili, A. (2005). Examining the New Influencers: A Self-Presentation Study of A-List Blogs. Journalism Q Mass Communication Quarterly 82 (4): 968-982.

Vos, T., \& Singer, J. B. (2014, Agosto). “Entrepreneurial Journalism: Shifting Journalistic Capital?” Comunicação aceite para apresentação na conferência da Association for Education in Journalism and Mass Communication, Montreal (Canadá).

Willnat, L., Weaver, D. H., \& Choi, J. (2013). The Global Journalist in the 21st Century. Journalism Practice 7 (2): 163-183.

$$
\text { 为头 }
$$

Recebido a 18-03-2014

Aceite a 05-05-2014 